\title{
Collaborative design of assessment criteria to improve undergraduate student engagement and performance
}

Laura J. Leslie \& Paul C. Gorman

\section{ABSTRACT}

Student engagement is vital in enhancing the student experience and encouraging deeper learning. Involving students in the design of assessment criteria is one way in which to increase student engagement. In 2011, a marking matrix was used at Aston University (UK) for logbook assessment (Group One) in a project-based learning module. The next cohort of students in 2012 (Group Two) were asked to collaboratively redesign the matrix and were given a questionnaire about the exercise. Group Two initially scored a lower average logbook mark than Group One. However, Group Two showed the greatest improvement between assessments, and the quality of, and commitment to, logbooks was noticeably improved. Student input resulted in a more defined, tougher mark scheme. However, this provided an improved feedback system that gave more scope for self-improvement. The majority of students found the exercise incorporated their ideas, enhanced their understanding, and was useful in itself.

\section{KEYWORDS}

Assessment design, marking matrix, student-centred, mechanical engineering, logbook

\section{Introduction}

\subsection{Collaborative approaches to assessment design}

Assessment is an increasingly important issue within higher education, and is central to the student experience (O'Donovan, Price, and Rust 2004). Furthermore, it is believed that the way students are assessed, how feedback is delivered, and the level of engagement with assessments is key to students learning (Gibbs and Simpson 2004).

Collaborative, student participation in the development of assessment criteria has been discussed in the literature at length (Healey, Flint, and Harrington 2014; Lyons 1989; Orsmond, Merry, and Reiling 2000; Searby and Ewers 1997). The merit of involving students in assessment criteria design has been argued to be important in the development of a deeper understanding of their assessments and a clearer concept of the subject (Searby and Ewers 1997). However, involving students in the design of assessment criteria does not automatically result in agreement on given marks. In some cases it has been found to increase disagreement between grades provided, for example, when comparing self, tutor and peer assessment (Orsmond, Merry, and Reiling 2000). 
It could be argued that a collaborative approach to the design of assessment criteria in itself is an endeavour that attempts to make the learning more student-centred. This type of learning can be defined in many ways, but in general, student-centred learning encourages the students to become more active in their learning and take greater responsibility and ownership in the learning process (Lea, Stephenson, and Troy 2003).

Collaboration between staff and students is moving further to the fore within higher education, and the Quality Assurance Agency (QAA) maintain that involving students in the development of the course, including assessments, can have a positive impact on the student experience and the course overall (2012). Furthermore, the QAA contend that collaboration with students enhances engagement, and means that staff and students work together more as partners (2012). This terminology echoes the rhetoric of student-centred education, whereby student involvement is paramount.

\subsection{Project-based learning}

Learning that is project-based is also argued to be more student-centred than traditional forms of teaching (Mills and Treagust 2003), and at Aston University, students within the Mechanical Engineering and Design Department undertake programmes which are based around the principles of Conceive, Design, Implement, Operate (CDIO) (CDIO 2015). The key modules within these programmes are project-based learning courses designed to develop graduates with technical knowledge and reasoning as well as personal, professional and interpersonal skills (Crawley 2002). The aims of CDIO are to resolve the barriers that prevent us from meeting the goals put forward over the last 50 years in terms of what engineering education should provide (Crawley 2001). The classes taught at Aston University are highly interactive, practical and project-based, with the emphasis on teamwork and active learning. The classes involve projects such as the building of an electric car and the development of a medical product. Projects involve hands on building of prototypes, both aesthetic and functioning, presentations, mock tradeshows and open air exhibitions of work. Assessment takes place in the form of individual reports, class tests and logbooks as well as group marks for prototypes and assessment day performances. The focus of this study was the logbook component of the assessment. Logbooks are a common learning and assessment tool for all of our project-based modules in study years one and two, and are also employed as part of a students' final year project. In addition, they are a component of the project-based module which is ongoing, that is, the logbook is used by the student from the first to the last day of the module and is an integral part of the students' learning process.

\subsection{Logbook assessment}

Logbooks are extremely important for engineers and the reasons for the use of logbooks varies widely from keeping a personal record of work, to being part of organisational policy or legal requirement (McAlpine et al. 2006). They may contain important data from a student's or engineer's work which otherwise would not be recorded (Hicks et al. 2005) and they can help measure a student's understanding of a project and level of critical thinking and contribution to their team (Huet et al. 2008). The teaching of logbook use and how students can improve their logbooks has been investigated previously (McAlpine, Hicks, and Culley 2008). In the project-based modules at Aston, logbooks are mandatory and are assessed as part of the course. Here we hope to improve students' perceptions and abilities in the keeping of a 'good logbook'. 
As in all learning environments, the type of feedback and the timing in which it is received, is important to the students in problem-based learning environments (Parikh, McReelis, and Hodges 2001). Students' logbooks at Aston were already being assessed using a marking matrix or rubric, as it was seen as a useful tool that helps to focus assessment. Matrixes (or rubrics) have several advantages over other feedback methods; students are clear on how the work is evaluated and assessed, the matrix allows very structured and clear feedback to the student for improvement purposes, they are quick and easy to use from a tutors perspective and the assessment is forced into being objective and consistent (Burke and Pieterick 2010a). In previous years, the task of keeping a logbook was introduced in the first two weeks of teaching period one, year one, in the project module. Lectures were given on logbooks, why they are kept, what they can be used for and what constitutes a 'good logbook'. Students were encouraged to read about logbooks online and to research logbooks in more detail themselves. The students were then asked to obtain and complete logbooks throughout the teaching period as a record of their thoughts, activities, designs, meetings etc. Mid-way through teaching period one, this was followed up by a 'logbook challenge' whereby a legal challenge was made on the students' logbooks to show them how a poor logbook could fail them in a legal situation, whereas a good logbook would aid them. At the end of the teaching period, these logbooks were submitted for tutor assessment.

\subsection{The project aims}

It was noticed that there were a portion of students who were not fully understanding or appreciating the importance of logbooks in this module. For example, in a number of cases, crucial elements were missing from students' logbooks and the overall quality of the logbooks required improvement. The hypothesis was that these issues could be approached and remedied through a more student/tutor collaborative approach.

Action research is the term describing research projects that may be undertaken by a teacher in order to change their future practices (Ferrance, 2000). The ultimate goal of these projects is often to find solutions to problems, improve student attainment or improve infrastructure. Here we have employed action research with the following aims:

1. To improve students' grades in logbook assessment.

2. To improve students' understanding of logbooks and their importance.

3. To enhance students' engagement with the process of keeping a logbook.

An intervention was proposed to actively involve students in the development of the assessment matrix used to mark their logbooks. Other studies that have employed this methodology have reported that students felt benefits such as a greater personal interest in the work, a feeling that their opinions were valued by lecturers and more motivation to work hard (Hernández 2007). However, the previous study cited was in a small class within a languages programme, and the authors could find little in the literature where this same methodology had been used in large cohorts of engineering students within project-based learning environments.

\subsection{Hypothesis}

The hypothesis was that if the students themselves had a say in the assessment criteria and mark scheme for their logbooks, that they would have a greater understanding of the principles of the logbook and also a greater awareness of how to complete the logbook to a 
high standard. As a result, it was also hoped that this process would result in better marks for the logbook assessment exercise.

This report details this Action Research project, what changes were made, and discusses the effects they had on first year student logbooks.

All methodology was submitted and received approval under the Aston University Educational Research Ethics Committee. 


\section{Methods}

\subsection{Students and assessments}

Students were assessed in two consecutive year groups, between the years of 2011 and 2013, both during year one of their studies. The first group shall be called Group One, and the second Group Two. Details of each of the groups and their assessment schedules can be seen in Table 1, where the number of students recorded is the number of students who completed all assessments.

\subsection{The action}

The action taken in this research project, for students in Group Two, was as follows:

1. Student input was used in the re-development of the marking matrix used to assess logbooks.

2. Students could see the matrix prior to the exercise of keeping a logbook.

3. The logbook challenge was replaced with a mid-teaching period logbook assessment.

Both student groups received taught information on logbooks in week one of teaching period one. Group One did not see the marking matrix prior to assessment, whereas Group Two was asked to revise the matrix after research into logbooks in week one. The process this took is described in more detail below.

Mid-way through teaching period one, Group One was taken through the logbook challenge, whereas Group Two had their logbooks marked using the revised matrix.

At the end of teaching period one, both Groups One and two had their logbooks marked, Group One with the original matrix, previously unseen, and Group Two with the revised matrix. In addition, Group Two had their logbooks marked at the end of teaching period two. The timeline for these events is shown in Figure 1.

\subsection{Taught material}

The taught material on logbooks included a lecture in week one of teaching period one on what makes a good logbook, what a logbook should contain, and what the importance of a logbook is and how it can be used. This was reasonably consistent for both student groups with only minor changes. The material was made interactive through the use of electronic voting systems and incorporated visual aids such as YouTube videos. Guidelines for the correct type, style and content of a logbook were provided, both during the session and afterwards electronically. The homework from this session was to obtain a suitable logbook and to begin using it by filling in the day's session and using it through the teaching period.

\subsection{Marking matrixes}

The original marking matrix is shown in Figure 2 and the revised version in Figure 3. As previously stated, Group One did not see the matrix until it was used to provide feedback following the first assessment. Group Two, however, were given the matrix to look at in their project groups. Each group consisted of between four and six students. Groups were given 
time to collate between them their research on logbooks, study the current matrix, and discuss amongst themselves how they thought the matrix could be improved.

Students had opportunity to voice their opinions to the class and then were given time in groups to edit, by hand, copies of the matrix at their tables. Once completed, these copies were collected and the comments used to develop the new matrix as shown in Figure 3.

This new matrix was based on the feedback, both written and verbal, from the students themselves. This included the class wide discussions, the submitted written revisions of the matrixes from each group, and discussions with a number of the groups in turn. The feedback was collated and discussed by the academic staff. The new matrix, though written by the staff, was formulated based on the students' suggestions.

This revised version was presented to the students in the afternoon session of the same day and students were again asked to look over it. At this point, a questionnaire was given to the students in order to establish their feelings about the exercise and whether the new matrix reflected their input.

\subsection{Questionnaire}

After the matrix exercise was completed with the Group Two students, and the adapted matrix had been presented back, four statements were posed. Answers were provided on a 5 point Likert agreement scale (from 'Strongly Disagree' to 'Strongly Agree'). The questionnaire was performed using an electronic voting system (Turning Technologies LLC., Ohio, USA). Students were asked to swap their numbered handsets in order for anonymity to be maintained. The following statements were posed to the students:

1. Statement 1 - The new marking matrix incorporates my ideas.

2. Statement 2 - The new marking matrix is an improvement.

3. Statement 3 - I better understand how the logbook will be assessed.

4. Statement $4-$ I feel the exercise was useful.

This approach was used in order to enquire as to whether the students had found the exercise useful, and whether they felt it had bettered their understanding of the logbook and how it would be assessed. Other methods such as focus groups, in depth questionnaires and discussions would have yielded richer data, however, the advantages of this short, in-session questionnaire meant a minimal effort for students, a high response rate, immediate feedback whilst the exercise was still fresh in their minds, and the practical time constraints of lecturing meant that the questionnaire needed to be concluded quickly. Therefore, although the questions were very limited, the approach and methodology was felt to be the most suitable for this project. 


\section{Results and discussion}

\subsection{Matrix re-design}

The use of a marking matrix has been explored in other studies, and has been shown to aid in the consistency of marking between markers, as well as being an excellent means of feedback to the students (Burke and Pieterick 2010a; Price and Rust 1999). The students did appear to respond well to the use of a matrix and to the exercise of re-designing the matrix, and this is explored more in the questionnaire results section. The matrix re-design did result in significant changes to the mark schemes (see Figure 2 for the original and Figure 3 for the revised matrix). These changes were based on the written and verbal feedback from the students, collated by the academics, and written into the new matrix.

The number of assessment sections was reduced from seven to five, following the amalgamation of some of the sections. The five areas were given different descriptions in the revised version compared to the original. These descriptions are more detailed and more precise in what is required than previously. The mark divisions for each area also have their own descriptions, detailing what is required to achieve each mark. These descriptions were also altered to reflect the students' comments, and again became more detailed and precise in what is required for each mark.

The resulting matrix is more descriptive, detailed and focussed on what is really required to gain marks in each assessment area. It is much less ambiguous than the original matrix. This resulted in a matrix with less scope for 'easy marks' and arguably a tougher mark scheme.

\subsection{Logbook marks}

\subsubsection{Assessment results}

The logbooks for each student group were assessed, Group One at the end of TP1 (1) and the end of TP2 (2). Group Two were assessed mid-way through TP1 (1), and at the end of TP1 (2) and TP2 (3). The timeline for assessment and feedback is shown in Table 1. The marks from each assessment were collected and analysed in order to compare between groups. Averages (means), ranges, standard deviations and student $t$-tests have been calculated and/or performed.

\subsubsection{Average marks}

In Table 2, the results from assessments of both groups are shown along with the mean assessment mark and range of marks in each group, the number of students who increased their marks between assessments, the average amount that these students increased their marks by, the number of students who received a decreased mark between assessments and the average percentage decrease in marks, and the number of students whose marks did not change between assessments. These groups only include statistics for students who submitted all pieces of coursework. If students scored 0 (absent) due to changing courses or leaving University, the data would not be a true representation of the action research.

The results of the average marks for each group during each assessment is most readily seen in Figure 4 and Table 2. 


\subsubsection{Trends in marks}

As well as the initial assessment marks for each group, the subsequent assessments and the difference in marks between assessments was also considered. This change in marks indicates how the feedback from the marking matrixes may have influenced the subsequent quality of the logbook.

The initial assessments showed a lower average mark for Group Two. However, the change in marks between subsequent assessments showed an upwards trend for Group Two, with a higher percentage of students improving on their marks between assessments. Between the first two assessments $60 \%$ of students in Group Two, as opposed to $46 \%$ in Group One, improved their mark, and in the third assessment for Group Two a total of $73 \%$ of students had increased their mark compared to the initial assessment.

In addition, the amount by which students improved their marks was also greater in Group Two than Group One. Between assessments one and two, those students with an increased mark in Group Two improved by an average of $12 \%$ as opposed to $11 \%$ in Group One, and between the third and first assessment, this average improvement had increased to $17 \%$ for Group Two.

As well as Group Two containing a higher percentage of students who improved their marks, and by a greater amount than Group One, there was also a smaller percentage of students who exhibited a decrease in their assessment marks. In Group One, 54\% of students had a drop in grades between their first and second assessments. Group Two however, had a 31\% drop between assessments one and two, and just $18 \%$ between the first and third assessments (Figure 5).

\subsubsection{Trends in grades}

Much as with the mean marks, trends in the grading structure can also provide information as to the change in the quality of logbooks being assessed. Non-submissions have not been included in these statistics, though fail marks have been.

Grades are determined as in Table 3 and the spread of grades at each assessment level for each group is shown in Table 4 and Figure 6.

Considering Group One, there is a clear pattern which varies little between assessments. There is a large proportion of students attaining high grades, with less students attaining each grade below the previous. The key difference in the trend between assessment 1 and 2 , is a lower percentage of students in the Fail grade. Otherwise the trend in grades is relatively unchanged.

The trend in grades for Group Two however, changes dramatically from assessment 1,2 and 3. The trend most closely resembles a traditional bell curve in assessment 1 (Figure 6c). The grades from assessment 2 (Figure 6d) however, appear to shift left towards the higher grades. And by assessment 3 (Figure 6e), the grades are weighted heavily towards the higher grades columns, that is, the 1 sts and $2: 1 \mathrm{~s}$.

\subsubsection{Statistical analysis}


A comparison between the assessment scores for students is provided in Table 5, including student $t$-test results. As previously described, students were removed from the sample if they had failed to submit work in any teaching period, as a zero score for un-submitted work would have skewed the data when looking for differences between the groups.

To summarise, results show that Group One students had no significant difference in their marks between assessments. However, Group Two students showed significant changes between assessments one and two, two and three and one and three.

\subsection{Questionnaire results}

As described in the methods section, four statements were posed to the Group Two students following the matrix re-development exercise and subsequent presentation of the revised matrix. The responses were provided anonymously.

The results from the students' responses are shown in Table 6 and Figure 7. In Table 6, the number of responses on the Likert scale is shown for each statement. The agreement statement with the highest response for each statement posed is shown in bold. If the 'Strongly Agree' and 'Agree' answers are combined, then these results show that $68 \%$ agreed that 'the new marking matrix incorporates my ideas'; 75\% agreed that 'the new marking matrix is an improvement'; $80 \%$ agreed that 'I better understand how the logbook will be assessed'; and 65\% agreed that 'I feel the exercise was useful'. Although numerous respondents neither agreed nor disagreed with the statements, the results show that very few disagreed. In order to better understand why students selected the 'Neither Agree nor Disagree' option, further investigation would be required in future projects as it is not possible to speculate as to the reasons for this response.

The results from the questionnaire show that the majority of students found the exercise useful, and that the new marking matrix included their ideas from the development stage and had helped them better understand how the logbook would be assessed. These results are very positive, and it could be argued that they indicate a level of ownership about the assessment process and logbook keeping exercise that possibly did not exist previously. This may be due simply to the extra time spent on the topic of logbooks in preparation to keeping the logbooks, but may also be due to the specific exercise of matrix re-development and discussion.

\subsection{Direct and indirect assessment results}

Because the students' answers to the questionnaire were anonymous, it is not possible to compare their answers to the questionnaire (indirect assessment) with their actual marks for the assessment (direct assessment). However, the fact that the majority of students felt that their ideas had been incorporated into the assessment process, and that their understanding of the assessment process was enhanced, means it could be argued that the indirect assessment is a strong indicator that student-centredness had increased as a result of involving students in the redesign of the assessment criteria. In parallel to this, an increase in grades was observed. Though we cannot directly link these two sets of results, it does appear to support the argument that student-centred practices, such as collaborative assessment design, not only improves students' perceptions of their learning but may also increase their grades.

\subsection{Limitations of the study}


This study has limitations, as with all research, and it is important to explore these limitations in order that only appropriate and valid conclusions may be drawn from the results.

The study has a relatively large number of participants, with 96 from Group One and 90 from Group Two, with a minimum response rate of 82 in the questionnaire of Group Two. This means that there is little debate as to whether the results can reliably represent the sample population, and greatly reduces the possibility that the results are skewed by a small sample. However, there were confounding variables between the groups. The first variable was the controlled variable of the marking matrix development, questionnaire and delivery. The other variables are as follows:

1. A different cohort of students, that is, different individuals - different groups of people will hold and express different opinions, so there is no sure way of knowing if the first and second groups of students would have responded in the same way in the different circumstances.

2. Different main projects during logbook keeping time - this is also true of the change in main project topic, where there is no way of knowing if the change in project topic or the intervention is the reasoning behind the changes in logbook keeping.

3. Different time periods between assessments: Group One $=2$ months, Group Two $=4$ months - the different time periods over which the logbooks were assessed is another possible reason, other than the intervention, for the difference in logbook grades and levels of engagement. Group One had an entire teaching period between assessments, whereas Group Two had only half a teaching period. It is possible that any improvements was partly due to the timing between assessments being reduced for Group Two, but this would require further investigation.

4. Methodology to gain insight into the students' experience of the exercise was limited

- with only a five-statement questionnaire, the foci is limited to the scope of our hypothesis and could not account for unexpected outcomes. This could have been improved through the use of focus groups and more in-depth questionnaires, for example. However, in the limited time available and with the use of the electronic voting system, a quick questionnaire and high response rate was achieved.

5. There is no knowledge of the students' marks outside of this exercise - students who improved, or did not, in this exercise, may have had a similar pattern in other assessments and therefore the pattern seen in this project is less likely to be down to the intervention.

\subsection{Reflections}

From a tutor's perspective, this study was an extremely interesting and positive experience to be involved in, and one which helped to generate enthusiasm in the tutor as well as the students. Prior to the implementation of the actions described, students were perfectly competent at keeping a logbook, but there appeared to be little appreciation for the importance of logbooks, especially in context to the real world. It was felt that logbooks were completed and submitted out of a need for course completion, rather than out of any perceived use, or commitment to engage fully with the task.

However, after the collaborative assessment intervention had been put in place, there was felt to be a definite shift in attitude towards the importance and appreciation of logbooks. Students asked more questions and were more involved and engaged with more enthusiasm and interest in the logbook exercises and assessments. At the end of term, students were required to write a report on the project they had worked on and were requested to submit 
logbooks prior to report submission. A high proportion of students reported the detrimental effect of submitting their logbooks prior to their reports, stating that they required their logbooks in order to inform and assist in the content of their reports. This was unexpected and had not occurred in previous years. It strongly suggested that students were no longer just keeping a logbook because they felt they had to, but were keeping a logbook correctly, using it as expected, and actually finding the logbook useful. 


\section{Conclusions}

There were three aims of this action research project, which were outlined in the introduction. To address the first point, the results show that the average mark for students initially decreased following the interventions. The reason for the lower average marks than Group One may be due to the students creating a more rigorous, detailed, and therefore tougher marking scheme, which by consequence meant lower marks than with the previous mark scheme. However, the students' grades did increase in between assessments, and it could be argued that the improvement provides evidence that the matrix was more useful to students by providing them with better, more detailed feedback, which allowed them to see more clearly where marks were obtained, and how improvements could be made ready for the next assessment. Improving the formative feedback process for students in this study may have made all the difference in this respect, as others argue that feedback is most effective when it is given regularly and when it is still relevant (Burke and Pieterick 2010a). However, further research would be needed in order to clarify the exact reasons for the improvement in marks between the two assessments.

It could be strongly argued that the intervention was a success in terms of students understanding and ownership of the logbook keeping process. Indeed, $80 \%$ of the students surveyed agreed that 'I better understand how the logbook will be assessed', and 75\% agreed that 'the new marking matrix is an improvement', which adds weight to this assertion. Despite the fact that the intervention did not result immediately in better marks as anticipated, it may have resulted in students having a much better appreciation of the importance of keeping a logbook and will hopefully encourage students to keep up good logbook practice throughout their academic and industrial careers.

In terms of engagement, the authors feel that the commitment to logbook keeping and the overall quality and consistency in student's logbooks was noticeably improved in student Group Two. Students in general asked more questions throughout the project about logbooks, were more involved in research into what makes a 'good logbook' and were generally more interested in keeping a good quality logbook throughout the project. The 'ownership' aspect of the logbooks was certainly improved, though not by a measureable quantity, but by the students' attitudes towards the keeping of a logbook.

The findings of this study are important to the teaching community at Aston University and beyond. They show that projects such as this can make an impact on student learning and the student experience. Although marks did not immediately increase (possibly due to the tougher criteria), the majority of students indicated that the process was useful, enhanced their understanding of the assessment criteria, was an improvement on the previous assessment, and that their ideas were incorporated. Furthermore, the general quality and care taken with the logbooks, and the increased sense of importance of the logbooks, may well result in improved future marks, and most importantly, improved logbook keeping in the workplace as graduates. The importance of this is extremely high, with non-academic skills such as communication being valued highly in engineering graduates (Markes 2006). This re-design of the marking matrix will continue forwards to subsequent year groups in CDIO classes for three reasons:

1. The observed benefits of this to the students.

2. To conduct further research to investigate the effects.

3. To continue to refine and improve the feedback process. 
Overall, this research project has provided some interesting insights into the potential benefits of student involvement in developing assessment criteria and has provided some interesting data regarding the impact it has on their learning experience.

However, further research would benefit from exploring these issues in more in-depth in terms of the qualitative nature of the project, in order to better understand the students' experiences and perceptions of the exercise they go through, and their feelings about keeping an engineering logbook. A comparative study between students who have and have not gone through this exercise to find out their views on the importance of logbooks would also be very interesting, and would add a stronger qualitative assessment to the findings.

\section{Acknowledgments}

The author would like to acknowledge members of the Centre for Learning Innovation and Professional Practice at Aston University who instigated and supported this action research project. Specifically Dr Panos Vlachopolous and Dr Sandy Cope. The author would also like to acknowledge the CDIO team and technical support at Aston University who supported this research project, specifically Prof Geoff Tansley, Dr Gareth Thomson and Dr Mark Prince, Mr David Palmer, Mr Ken Little and Mrs Mahvash Miri. The author would also like to thank the students who took part in the optional questionnaire.

\section{Disclosure statement}

No potential conflict of interest was reported by the authors.

\section{References}

Burke, D., and J. Pieterick. 2010a. Giving Students Effective Written Feedback. Berkshire: Open University Press.

CDIO. “CDIO.org.” http://www.cdio.org/. CDIO. 2015. www.cdio.org, accessed 13/07/2015.

Crawley, E. F. 2001. "The CDIO Syllabus A Statement of Goals for Undergraduate Engineering Education." CDIO Syllabus Report, cdio.org.

Crawley, E. F. 2002. "Creating the CDIO Syllabus, A Universal Template for Engineering Education." Paper Presented at the Frontiers in Education, 2002. FIE 2002. 32nd Annual, 2002.

Ferrance, Eileen. 2000. Action Research. In Themes in Education, edited by LAB, 1-33. Providence, RI: Northeast and Islands Regional Educational Laboratory At Brown University.

Gibbs, Graham, and Claire Simpson. 2004. "Conditions Under which Assessment Supports Students' Learning.” Review of. Learning and Teaching in Higher Education 1 (1): 3-31.

Gibbs, Graham, and Claire Simpson. 2010b. Giving Students Effective Written Feedback. Berkshire: Open University Press. 
Healey, M., A. Flint, and K. Harrington. 2014. "Engagement Through Partnership: Students as Partners in Learning and Teaching in Higher Education." In Report by The Higher Education Academy, July 2014.

Hernández, R. 2007. Students' Engagement in the Development of Criteria to Assess Written Tasks. From the REAP International Online Conference on Assessment Design for Learner Responsibility.

Hicks, B. J., G. Huet, S. J. Culley, and H. McAlpine. 2005. "A Study of the Information Content of the Engineer's Logbook." In Proceedings ICED 05, The 15th International Conference on Engineering Design. Melbourne, Australia. 15-18/08/2005, 1-12.

Huet, Greg, Bernard Sanschagrin, Martine Gagnon, Daniel Spooner, Aurélian Vadean, and Ricardo Camarero. 2008. "The Assessment of Student Teamwork to Promote Cdio Learning Objectives." Paper Presented at the Proceedings of the 4th International CDIO Conference, Gent, June 16-19.

Lea, Susan J., David Stephenson, and Juliette Troy. 2003. "Higher Education Students' Attitudes to Student-centred Learning: Beyond 'Educational Bulimia'?” Review of. Studies in Higher Education 28 (3): 321-34. doi:10.1080/03075070309293.

Lyons, Paul R. 1989. “Assessing Classroom Participation.” Review of. College Teaching 37 (1): $36-8$.

Markes, Imren. 2006. "A Review of Literature on Employability Skill Needs in Engineering." Review of. European Journal of Engineering Education 31 (6): 637-50. doi:10.1080/03043790600911704.

McAlpine, H. C., B. J. Hicks, and S. J. Culley. 2008. "Investigating the Structure and Organisation of Engineering Logbooks for More Effective Re-Use." Review of. 10th International Design Conference - Design 20081 and 2 (48): 841-8.

McAlpine, H., B. J. Hicks, G. Huet, and S. J. Culley. 2006. "An Investigation into the Use and Content of the Engineer's Logbook." Review of. Design Studies 27 (4): 481-504.

Mills, Julie E, and David F Treagust. 2003. "Engineering Education - Is Problem-based or Project-based Learning the Answer?" Review of. Australasian Journal of Engineering Education 3 (2): 2-16.

O’Donovan, Berry, Margaret Price, and Chris Rust. 2004. "Know What I Mean? Enhancing Student Understanding of Assessment Standards and Criteria." Review of. Teaching in Higher Education 9 (3): 325-35. doi:10.1080/1356251042000216642.

Orsmond, Paul, Stephen Merry, and Kevin Reiling. 2000. "The Use of Student Derived Marking Criteria in Peer and Self-Assessment." Review of. Assessment \& Evaluation in Higher Education 25 (1): 23-38. doi:10.1080/02602930050025006.

Parikh, Amish, Kylen McReelis, and Brian Hodges. 2001. "Student Feedback in Problem Based Learning: A Survey of 103 Final Year Students Across Five Ontario Medical 
Schools.” Review of. Medical Education 35 (7): 632-36. doi:10.1046/j.13652923.2001.00994.x.

Price, Margaret, and Chris Rust. 1999. "The Experience of Introducing a Common Criteria Assessment Grid Across an Academic Department." Review of. Quality in Higher Education 5 (2): 133-44. doi:10.1080/1353832990050204.

QAA. 2012. "UK Quality Code for Higher Education. Part B: Assuring and Enhancing Academic Quality. Chapter B5: Student Engagement." In The Quality Assurance Agency for Higher Education.

Searby, Mike, and Tim Ewers. 1997. "An Evaluation of the Use of Peer Assessment in Higher Education: A Case Study in the School of Music, Kingston University." Review of. Assessment \& Evaluation in Higher Education 22 (4): 371-83. 


\section{Tables}

Table 1 Overview of student groups taking part in study and assessment schedules (TP=Teaching Period)

\begin{tabular}{|l|l|l|}
\hline Group & One & Two \\
\hline Year of Study & One & One \\
\hline Number of students & 96 & 90 \\
\hline Matrix & Original & Redesigned \\
\hline Interim assessment & Logbook challenge Mid TP 1 & Matrix re-design Start TP1 \\
\hline Logbook Assessment 1 & End TP 1 & Mid TP 1 \\
\hline Logbook Assessment 2 & End TP 2 & End TP 1 \\
\hline Logbook Assessment 3 & N/A & End TP 2 \\
\hline Questionnaire & N/A & Mid TP 1 \\
\hline
\end{tabular}

Table 2 Group results showing mean assessment marks and statistics for increased and decreased marks for both groups. In each case, the comparison is made to the previous assessment, unless otherwise stated. All values are rounded to the nearest whole number.

\begin{tabular}{|l|c|c|c|c|c|c|c|}
\hline Group & $\begin{array}{c}\text { Assessment } \\
\text { Session }\end{array}$ & $\begin{array}{c}\text { Mean } \\
\text { mark } \\
\text { (Range) } \\
\mathbf{\%}\end{array}$ & $\begin{array}{c}\text { Students } \\
\text { with } \\
\text { increasing } \\
\text { marks \% }\end{array}$ & $\begin{array}{c}\text { Average } \\
\text { increase } \\
\text { of } \\
\text { marks } \\
\text { \% }\end{array}$ & $\begin{array}{c}\text { Students } \\
\text { with } \\
\text { decreasing } \\
\text { marks \% }\end{array}$ & $\begin{array}{c}\text { Average } \\
\text { decrease } \\
\text { \% }\end{array}$ & $\begin{array}{c}\text { Students } \\
\text { with no } \\
\text { change } \\
\text { in } \\
\text { marks } \\
\text { \% }\end{array}$ \\
\hline One & 1 & $\begin{array}{c}\mathbf{6 3} \\
(20-93)\end{array}$ & - & - & - & - & - \\
\hline Two & 1 & $\begin{array}{c}\mathbf{6 2} \\
(22-85)\end{array}$ & 46 & 11 & 54 & -10 & 0 \\
\hline & $26-86)$ & - & - & - & - & - \\
\hline & 3 & $\begin{array}{c}\mathbf{6 2} \\
(26-83)\end{array}$ & 60 & 12 & 31 & -6 & 9 \\
\hline & $\begin{array}{c}\text { Comparison } \\
\text { between 1 } \\
\text { and 3 }\end{array}$ & - & 73 & 17 & 18 & -12 & 9 \\
\hline
\end{tabular}

Table 3 Grade boundaries for percentage marks in logbook assessment

\begin{tabular}{|l|l|}
\hline Mark (\%) & Grade \\
\hline $70-100$ & $1^{\text {st }}$ \\
\hline $60-69$ & $2: 1$ \\
\hline
\end{tabular}




\begin{tabular}{|l|l|}
\hline $50-59$ & $2: 2$ \\
\hline $40-49$ & $3^{\text {rd }}$ \\
\hline $0-39$ & Fail \\
\hline
\end{tabular}

Table 4 Proportions of students at each grade level at each assessment for both groups

\begin{tabular}{|l|c|c|c|c|c|c|}
\hline \multirow{2}{*}{ Group } & \multirow{2}{*}{ Assessment } & \multicolumn{5}{|c|}{ Percentage of students at each grade } \\
\cline { 3 - 7 } & & $\mathbf{1 s t}$ & $\mathbf{2 : 1}$ & $\mathbf{2 : 2}$ & 3rd & Fail \\
\hline Group 1 & $\mathbf{1}$ & 35 & 27 & 19 & 8 & 10 \\
\hline Group 1 & $\mathbf{2}$ & 34 & 28 & 20 & 11 & 6 \\
\hline Group 2 & $\mathbf{1}$ & 10 & 28 & 26 & 26 & 9 \\
\hline Group 2 & $\mathbf{2}$ & 25 & 30 & 21 & 8 & 8 \\
\hline Group 2 & $\mathbf{3}$ & 36 & 24 & 16 & 7 & 6 \\
\hline
\end{tabular}

Table 5 Statistical comparison values for all sets of assessment marks for each group including student t-test values. Assessment values and standard deviation values are shown to one decimal place.

\begin{tabular}{|c|c|c|c|c|}
\hline Group & Assessment & $\begin{array}{l}\text { Mean } \\
\text { assessment } \\
\text { value }(\%)\end{array}$ & $\begin{array}{l}\text { Standard } \\
\text { Deviation }\end{array}$ & t.test \\
\hline \multirow[t]{2}{*}{ One } & One & 62.5 & 15.6 & \multirow{2}{*}{$\begin{array}{l}t(96)=0.521 \\
p=0.604\end{array}$} \\
\hline & Two & 61.8 & 13.1 & \\
\hline \multirow[t]{6}{*}{ Two } & One & 56.8 & 12.2 & \multirow{2}{*}{$\begin{array}{l}t(90)=-4.559 \\
p=0.000\end{array}$} \\
\hline & Two & 62.2 & 11.2 & \\
\hline & One & 56.8 & 12.2 & \multirow{2}{*}{$\begin{array}{l}t(90)=-7.592 \\
p=0.000\end{array}$} \\
\hline & Three & 67.5 & 13.5 & \\
\hline & Two & 62.2 & 11.2 & \multirow{2}{*}{$\begin{array}{l}t(90)=-4.794 \\
p=0.000\end{array}$} \\
\hline & Three & 67.5 & 13.5 & \\
\hline
\end{tabular}

Table 6 Percentage agreement results from the four statements, with the highest response for each statement in bold. Percentages rounded to the nearest whole number. Number of responses in brackets.

\begin{tabular}{|l|c|c|c|c|c|c|}
\hline Statement & $\begin{array}{l}\text { Strongly } \\
\text { Disagree }\end{array}$ & Disagree & $\begin{array}{c}\text { Neither } \\
\text { Agree nor } \\
\text { Disagree }\end{array}$ & Agree & $\begin{array}{c}\text { Strongly } \\
\text { Agree }\end{array}$ & $\begin{array}{c}\text { Total } \\
\text { number of } \\
\text { responses }\end{array}$ \\
\hline $\begin{array}{l}\text { Statement 1 } \\
\text { The new } \\
\text { marking } \\
\text { matrix } \\
\text { incorporates } \\
\text { my ideas }\end{array}$ & $3 \%(3)$ & $1 \%(1)$ & $28 \%(26)$ & $\mathbf{5 3 \% ( 4 9 )}$ & $15 \%(14)$ & 93 \\
\hline Statement 2 & $1 \%(1)$ & $8 \%(7)$ & $16 \%(14)$ & $\mathbf{5 1 \% ( 4 4 )}$ & $24 \%(21)$ & 87 \\
\hline
\end{tabular}




\begin{tabular}{|l|l|l|l|l|l|l|}
\hline $\begin{array}{l}\text { The new } \\
\text { marking } \\
\text { matrix is an } \\
\text { improvement }\end{array}$ & & & & & & \\
\hline $\begin{array}{l}\text { Statement 3 } \\
\text { I better } \\
\text { understand } \\
\text { how the } \\
\text { logbook will } \\
\text { be assessed }\end{array}$ & $1 \%(1)$ & $7 \%(6)$ & $12 \%(10)$ & $\mathbf{5 8 \%}(\mathbf{5 0})$ & $22 \%(19)$ & 86 \\
\hline $\begin{array}{l}\text { Statement 4 } \\
\text { I feel the } \\
\text { exercise was } \\
\text { useful }\end{array}$ & $2 \%(2)$ & $11 \%(9)$ & $22 \%(18)$ & $\mathbf{5 0 \% ( 1 2 )}$ & $15 \%(12)$ & 82 \\
\hline
\end{tabular}




\section{Figures}

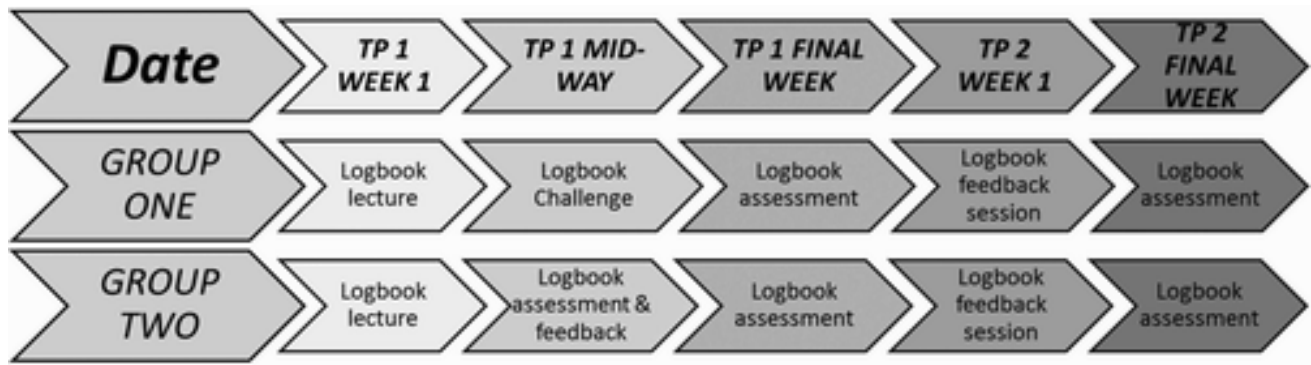

Figure 1 Timeline for both student groups, showing assessment dates and formats (TP=Teaching Period)

\begin{tabular}{|c|c|c|c|c|c|c|}
\hline & Detifect - 10 & Very $\cos d=8$ & Satialoctory/0a - 6 & Poot -4 & Unsatidectory = 2 & Unapporent = 0 \\
\hline $\begin{array}{l}\text { Periseveranke of } \\
\text { logbosk entries }\end{array}$ & $\begin{array}{l}\text { [Some defal level was I- } \\
\text { II] }\end{array}$ & (Moordy some wis :-11]) & $\begin{array}{l}\text { Isome moets not as } \\
\text { complete as eftent? }\end{array}$ & $\begin{array}{l}\text { Most weeds bocking } \\
\text { detallyot present? }\end{array}$ & $\begin{array}{l}\text { "Most meeks not } \\
\text { presentl }\end{array}$ & $\begin{array}{l}\text { Wo sopboak entres } \\
\text { for any weres] }\end{array}$ \\
\hline $\begin{array}{l}\text { Pates doted } 5 \\
\text { signed and } \\
\text { heoded }\end{array}$ & 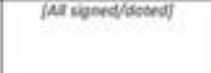 & $\begin{array}{l}\text { Prss woned/ } \\
\text { dothd/hroded] }\end{array}$ & 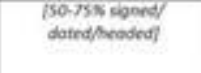 & 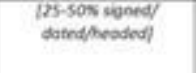 & $\begin{array}{l}\text { 10.-2ss ingued/ } \\
\text { dathe/meoded] }\end{array}$ & $\begin{array}{l}\text { los wonnd/ } \\
\text { dotrefprodedf }\end{array}$ \\
\hline Ceeble weriting & far woble + good boyoulf & 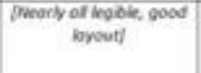 & $\begin{array}{l}\text { [Wosty hoble, } \\
\text { reovoosble hyout] }\end{array}$ & 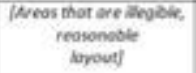 & 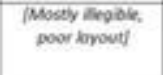 & 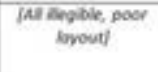 \\
\hline 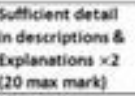 & 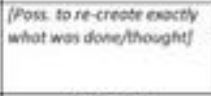 & 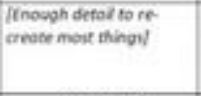 & $\begin{array}{l}\text { finowigh detsil to work } \\
\text { out most of whot nos } \\
\text { donel }\end{array}$ & 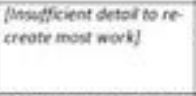 & 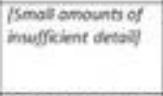 & INa destar at all \\
\hline $\begin{array}{l}\text { Quality of } \\
\text { dramines: }\end{array}$ & IEsentent/f & [Wery good] & ICould be better but od & $\begin{array}{l}\text { Montly poor soolity but } \\
\text { preseney }\end{array}$ & 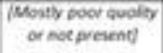 & Thot prevent] \\
\hline $\begin{array}{l}\text { Eeflections - } \\
\text { number of } \\
\text { entries }\end{array}$ & Pormovel & (7) & 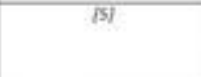 & [3] & (ii) & $\begin{array}{l}\text { Do-not wen } \\
\text { monthoned }\end{array}$ \\
\hline $\begin{array}{l}\text { Quality of } \\
\text { reflections }\end{array}$ & 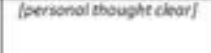 & 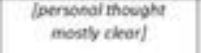 & 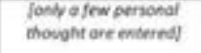 & 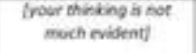 & $\begin{array}{l}\text { Mery lecte of vour } \\
\text { misibg id evident] }\end{array}$ & [Not prenent] \\
\hline \multirow{2}{*}{\multicolumn{6}{|c|}{ 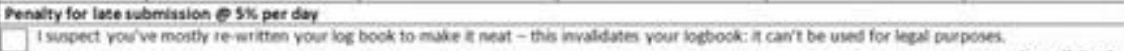 }} & deris \\
\hline & & & & & Doses. overall Grade & \\
\hline
\end{tabular}

Figure 2 Original Marking Matrix

\begin{tabular}{|c|c|c|c|c|c|c|}
\hline \multirow[b]{2}{*}{ 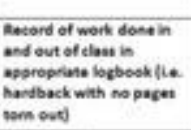 } & Derfiect - 10 & Very Good - I & Good-6 & Poar - 4 & Unsatiafastory -2 & Unowaluble -0 0 \\
\hline & 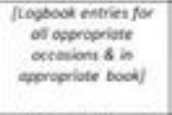 & 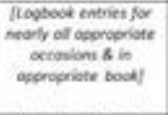 & 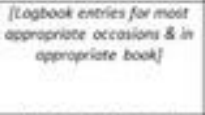 & 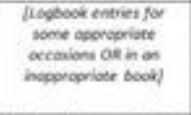 & 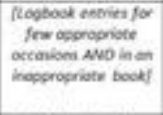 & 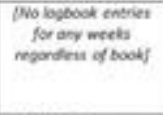 \\
\hline 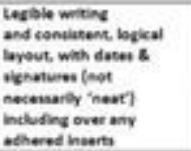 & 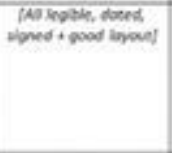 & 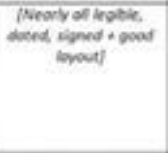 & 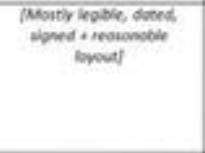 & 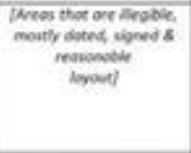 & 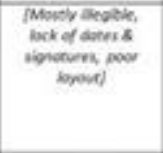 & 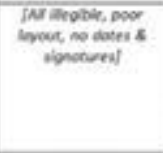 \\
\hline 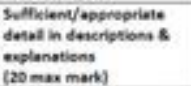 & 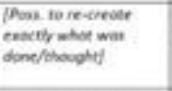 & 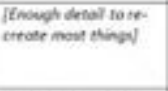 & 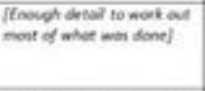 & 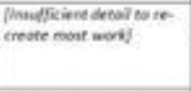 & $\begin{array}{l}\text { Ismid anowise of } \\
\text { inudifient detall }\end{array}$ & [No detail of ally \\
\hline 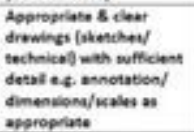 & 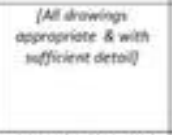 & 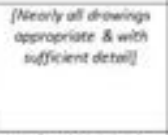 & 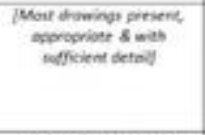 & 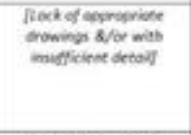 & 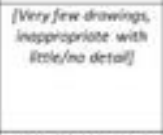 & INodhiminger 8 nos \\
\hline \multirow[t]{2}{*}{ 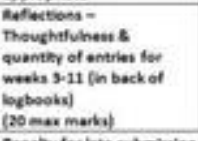 } & 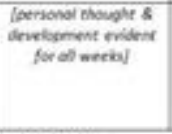 & 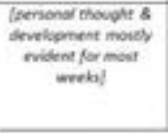 & 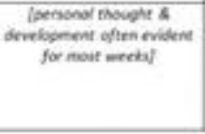 & 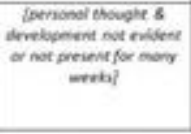 & 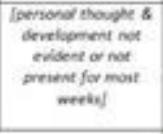 & 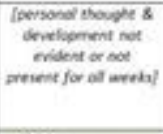 \\
\hline & \multicolumn{5}{|c|}{ 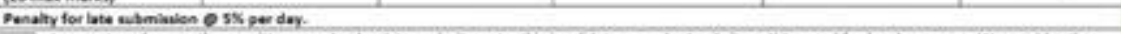 } & $\operatorname{sen}$ \\
\hline \multicolumn{6}{|c|}{ 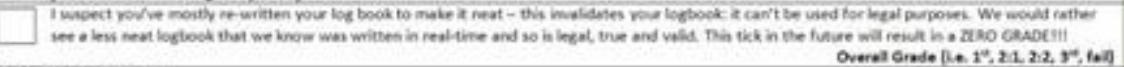 } & \\
\hline
\end{tabular}


Figure 3 Revised Marking Matrix

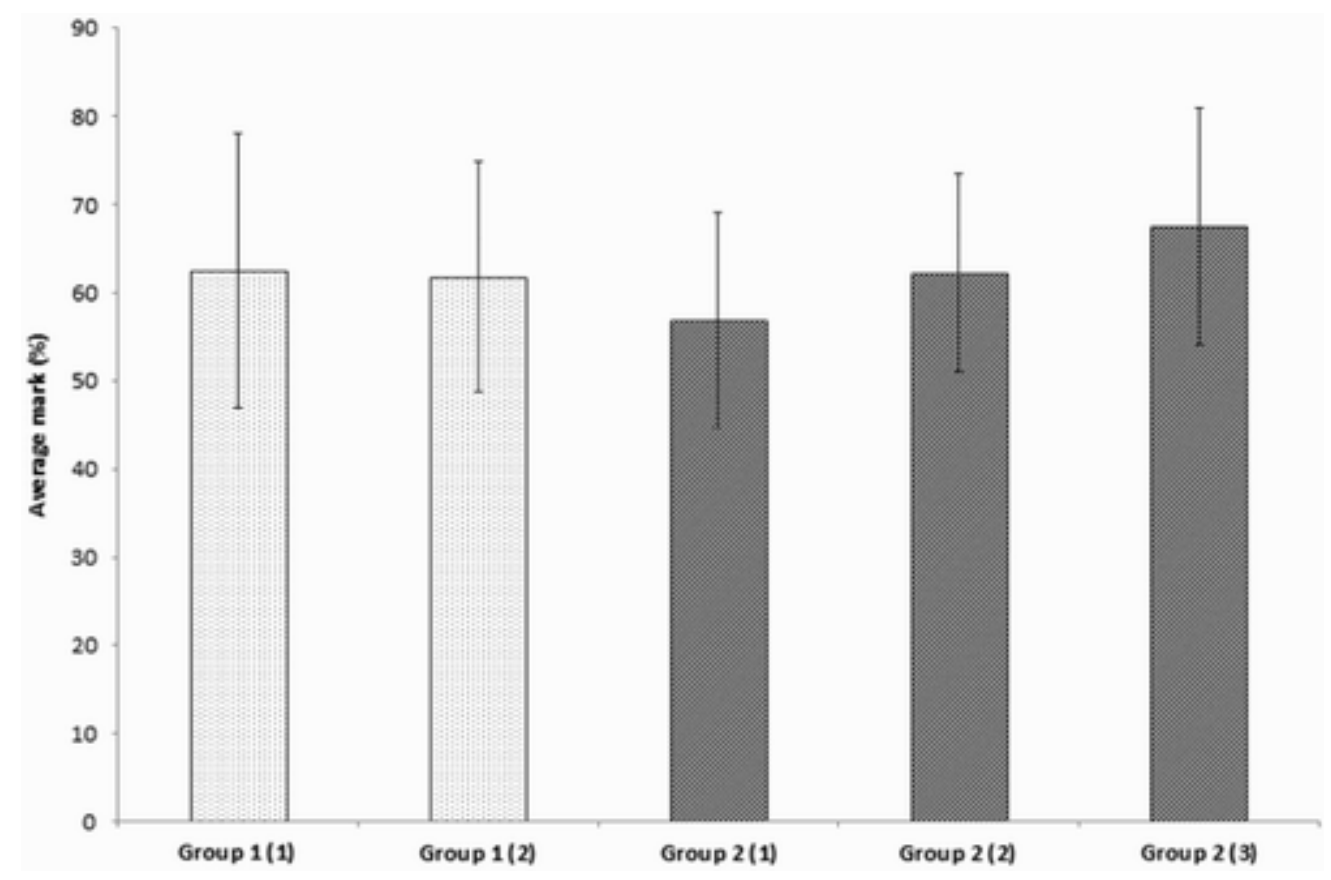

Figure 4 Average (mean) marks for each group at each assessment. Bracketed number is assessment number i.e. (2) is second assessment. Error bars showing \pm 1 standard deviation

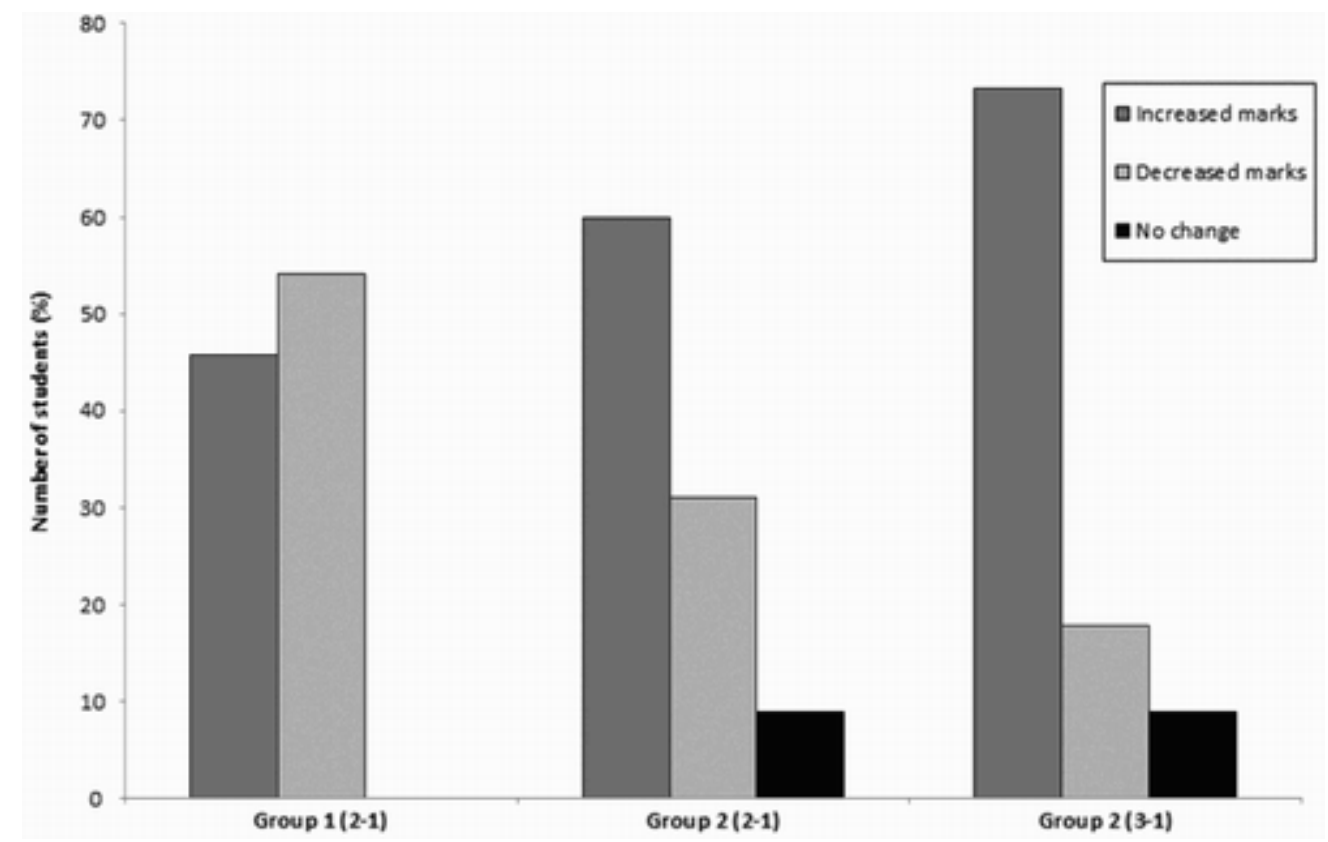

Figure 5 Percentage of students with increased, decreased, or no change in marks between assessments. The bracketed numbers relate to the assessments which are being compared i.e. (3-1) indicates that the differences in marks are between the third and first assessments. 
(a)

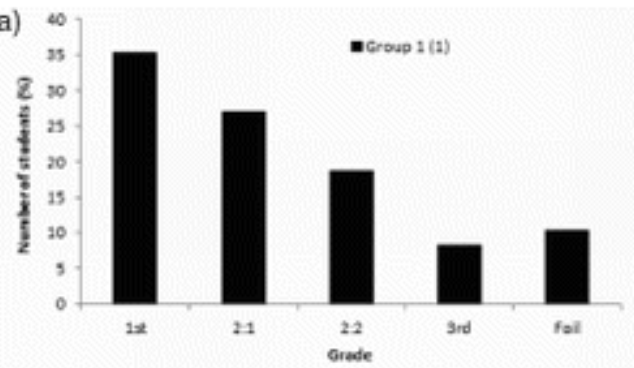

(b)

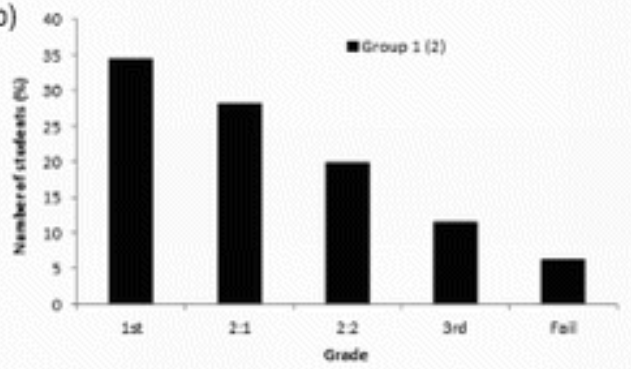

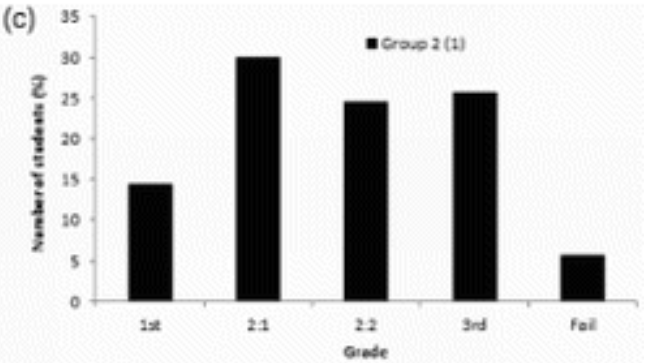

(d)
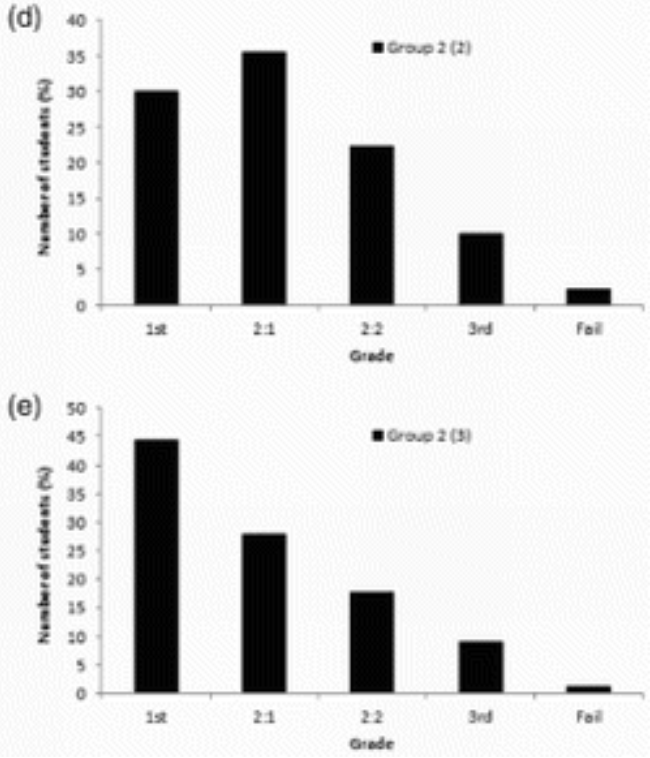

Figure 6 (a) Grade marks for Group One in assessment one (b) Grade marks for Group One in assessment two (c) Grade marks for Group Two in assessment one (d) Grade marks for Group Two in assessment two (e) Grade marks for Group Two in assessment three

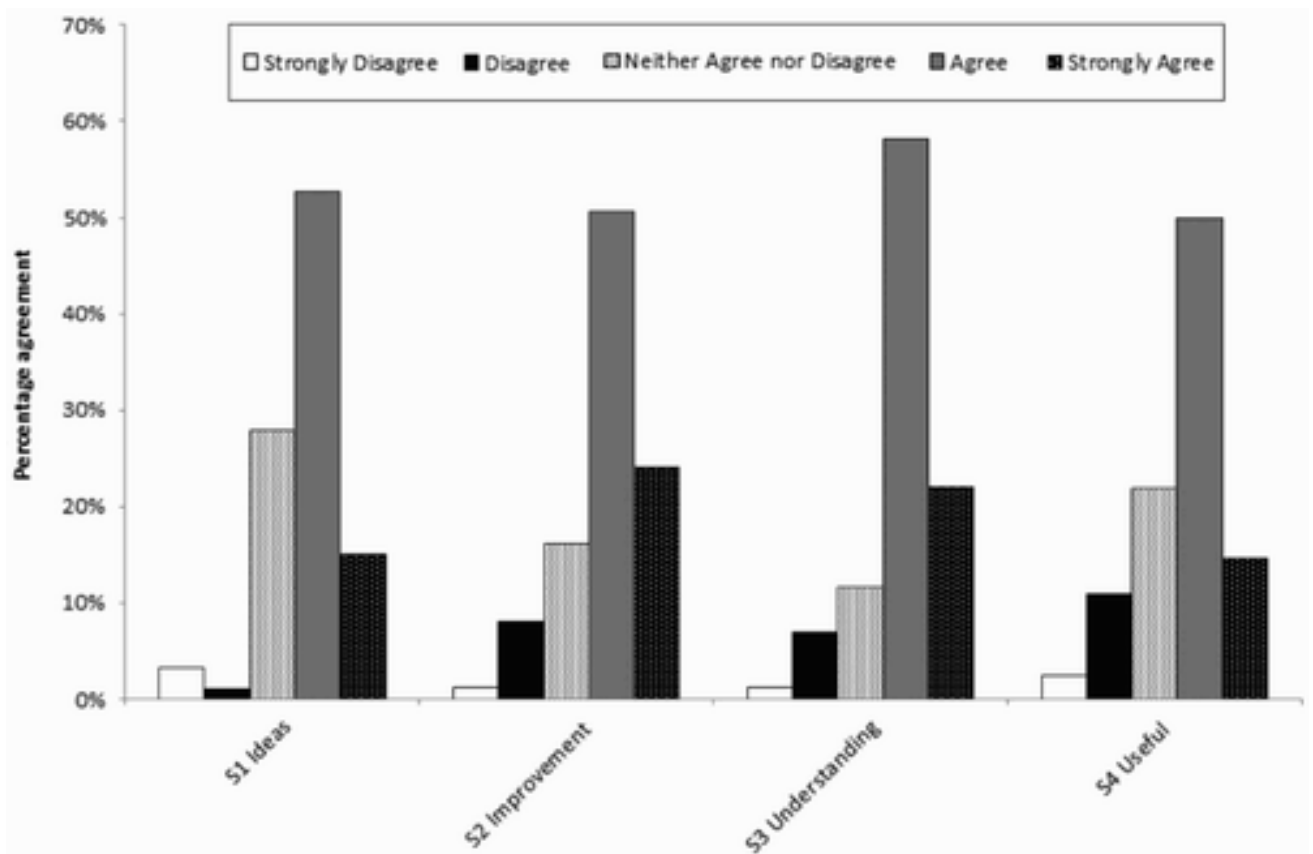

Figure 7 Statements with response rates of agreement 